\title{
DESIGN LOADINGS
}

\author{
G.W. Butcher*
}

\section{SYNOPSIS}

This paper covers those parts of the loadings code NZS 4203 which relate to dead, live and snow loads. Seismic and wind loads are dealt with in other papers.

The parts of the code discussed are Part 2 and that section of Part 1 dealing with design load equations and load factors.

\section{INTRODUCTION}

NZS 4203 is intended to provide a basis for the design of all buildings irrespective of the type of structure and materials used. The design philosophy and the resulting principles laid down by the code will form the basis for future revisions of structural material codes produced by S.A.N.Z.

The building bylaw section of the draft is of particular importance since it clearly states the requirements for safety and serviceability to be considered in the design process. Covering these aspects, N2S 1900.8 states:

The design and construction of any building shall be such that :

(a) All loads likely to be sustained during the life of the building will be sustained with an adequate margin of safety;

(b) Deformations of the building will not exceed acceptable levels;

At an early stage of code revision consideration was given to adopting probabilistic design methods rather than the deterministic methods (using strength or the alternative design) which had been used up to that time. Alternative design methods examined were: 1. The semi-probabilistic method (limit
state).

2. The probabilistic method.

The limit state method has certain attractions from a design office point of view since some of the concepts have already been introduced in the strength method of design. The concepts referred to are those relating to strength such as a statistical approach to concrete strengths and capacity reduction factors together with load factors (even though these had been evaluated deterministically i.e. on the basis of experience and engineering judgement) applying to service loads.

However, at that time it was not clear

* Civil Engineer; Partner, Morrison, Cooper and Partners, Wellington. whether limit state was just a stage in the development of a fully probabilistic design method. If this was true then to adopt limit state for the loading code and following on from this all structural materials codes could result in delays in embracing a fully probabilistic design method in the future.

The probabilistic method presents many difficulties of implementation in a practical code for design office use, particularly with regard to the treatment of earthquake and wind.

The decision was made to retain a deterministic approach for this code revision but to keep both design methods under review and where possible encourage further studies.

One direct result of this is the study recently carried out by Reid (1) currently under review by members of the committee.

Other significant developments have been the introduction of BSCPIIO (2) and ISO 2394 (3) together with the circulation of drafts of ISO $25 \mathrm{E}$ (4) and SAA DR 74056 (5) all relating to the limit state design method.

\section{DESIGN LOADS}

Design loads may be defined as the relevant service loads (dead, live or other loads) or in limit state terminology the characteristic loads multiplied by an appropriate load factor.

This is a perfectly general definition which applies to ultimate strength or ultimate limit state and serviceability requirements or serviceability limit states as well as the design method adopted whether strength design or alternative design or limit state. For strength or load factor design load factors are generally greater than 1.0 except for load combinations for reversal.

For the alternative design method and for checking serviceability requirements load factors of 1.0 or less are used.

Design load equations from Part 1 covering various combinations of loading for both the strength and alternative design methods are summarised in Table A. It should be noted that in the table design load equations for the alternative design method are treated somewhat differently from the draft in that a load factor of 1.0 is included where appropriate.

\section{LOAD FACTORS}

Load factors cannot be compared alone 
since they are just one part of an overall or global factor of safety which also includes consideration of member strength.

The load factor may be related to the capacity reduction factor as follows:

$$
\gamma S=\phi R
$$

Where $\gamma$ is the load factor

$S$ is the load effect

$\phi$ is the capacity reduction factor and

$R$ is the nominal strength of the member.

Using load factors and $\phi$ factors from ACI 318-71 (6) the following values of the overall or Global factor of safety may be calculated.

$$
\begin{array}{lll} 
& D=I & D=2 \mathrm{~L} \\
\phi=0.9 & 1.72 & 1.67 \\
\phi=0.7 & 2.21 & 2.14
\end{array}
$$

In determining gyerall safety the commentary to ACI 318-63 (7) suggests the following items need to be evaluated or assessed.

A. Those Factors which can Produce Overload

1. Inaccuracies in the design load assumption.

2. Variation from assumed load distribution.

3. Future changes in loads.

4. Frequency of loading and impact.

5. Inaccuracies in the analysis.

B. Factors which can Produce Understrength Members

1. Design inaccuracies in sizing and proportioning of members.

2. Lower than assumed material strength.

3. Variations in member sizes.

4. Other construction variations.

C. Factors which can Influence the Degree of Required Safety

1. The importance of members in relation to the overall stability of the structure.

2. The behaviour of a member at ultimate load.

3. The occupancy and type of structures.

4. The seriousness of failure from a safety of life or financial loss viewpoint.

5. The economics of additional safety.

Consideration of these items leads to an allocation between load factors and $\phi$ with some overlap as follows:

Load Factors

$$
\mathrm{Al}-5, \mathrm{Bl} \& \mathrm{~B} 4
$$

Capacity Reduction Factor $\phi \mathrm{Bl}-4, \mathrm{Cl} \& \mathrm{C} 2$

In the end, however, load factors for strength design in most codes have been based upon the criterion of achieving approximately the same degree of overall or global safety as that achieved by working stress design.

A comparison of load factors and design load equation for various codes is set out in Table $\mathrm{B}$.

ACI 318-71 (6) has been used as the basis for load factors and design load equations in the draft code.

\section{DISCUSSION ON THE DESIGN LOAD REQUIRE- MENT OF DZ 4203 PART 1}

Design Load Combinations: Strength Method

The existing Chapter 8 "Basic Design Loads" is based upon the use of the working stress method of design (now called the alternative method). Apart from Clause 8.8 relating to stability there are no provisions for load factors and design load equations for loading combinations. Strength design of reinforced concrete is covered by NZS $3101 \mathrm{P}$ (8) and load factors and design load equations are included in this document.

As stated earlier it is intended that NZS 4203 cover all structural materials so that the provisions of Clause 1.3.2 will supercede the requirements of NZS $3101 \mathrm{P}$ (8).

The load factors and load equations have been derived from ACI $318-71$ (6). A load combination probability factor of 0.75 has been applied to load combinations involving dead and live loads and wind or earthquake while for dead and snow loads and wind a factor of 0.85 has been used. For both snow and wind the design loads are based upon return periods of 50 years.

For the deterministic approach to gravity loads adopted by the code, only dead and live loads are separated. From a probabilistic viewpoint further subdivision of loads is necessary. If live loads were classified into short and long term loads a more rational treatment of the small probability of short term loads being present during earthquake attack is possible.

The present procedure of reducing the live load to either $\mathrm{D} / 10$ or $\mathrm{L} / 3$ or $2 \mathrm{~L} / 3$ as the contribution of live load to the seismic load has no rational basis and presumably can only be justified by experience.

An important change has been made with the elimination of the load factor to be applied to $\mathrm{E}$. The basic seismic coefficient (given in Fig. 3) has been increased by $25 \%$ so that $E$ as calculated is the design earthquake load for use in strength design.

Clause 1.3 .2 .6 covers loading where the effects of differential settlement. creep, shrinkage and temperature may be significant insofar as the serviceability requirements of the structure are concerned. The same clause in the original draft was based upon Clause 9.3.7 of A.C.I. 318-71 but this has been drastically altered in the final version of the code.

For both reinforced concrete and for structural steel these effects do not significantly influence the ultimate strength of a section (apart from buckling loads) since deformations produced by these causes are usually much less than those at collapse.

In combining these effects with service loads to determine their affects on the serviceability of the structure realistic values for the actual dead live and other loads should be used. This may mean coefficients of 1.0 or less. 
Similar requirements are set out in Clause 1.3 .3 .6 applying to the alternative method.

\section{Design Load Combinations: Alternative Method}

This clause sets out in logical order the design loads to be used in the alternative or working stress method of design.

A significant change is the inclusion of equations to cover reversal of load under wind and earthquake where only dead load is available to stabilise the members.

As $E$ is now calculated as a design load for strength design a load factor of 0.8 is necessary.

Higher working stresses are permitted by the material codes for combinations of loads with wind, or earthquake.

\section{DISCUSSION ON THE REQUIREMENTS OF NZS 4203 PART 2 AND CHANGES FROM CHAPTER 8 CIAUUSES $8.11-8.26$}

\subsection{General:}

This part of the code has been expanded significantly not only to cover additional loading cases but also for greater clarity and ease of use.

\subsection{Dead Loads}

There is no New Zealand standard relating to weights of materials and construction. Suitable overseas standards which may be used in lieu are BS 648: 1964 (9) and AS 1170 Fart $1-1971$ (10) Appendix A.

It has always been assumed that dead loads can be calculated with accuracy.

The commentary on ACI 318-71 (6) for instance states "A greater factor is applied to live load than to dead load since dead load can be determined with reasonable accuracy ......"

It should be recognised that variations in the dead load of the structure can occur from that assumed by the designer (the variation may be of the order of 20 to 25 per cent). These may occur due to:

1. Estimates made from incomplete drawings.

2. Changes in materials used.

3. Construction alterations.

4. Changes in moisture content.

5. Differences between assumed and as

built dimensions.

The dangers of being too conservative in estimating dead loads should also be realised when dealing with reversal of load with stability dependent on the level of dead load.

Regular reappraisal and correction if necessary should be carried out as the calculations proceed.

\subsection{Partitions:}

All types of partitions are now to be treated as dead load instead of only fixed partitions as in the past. The allowance for moveable and future partitions is however made in the same way as in the previous code using an equivalent distributed load. The reason for treating partitions in this way is to save computational work since it can be argued they should be treated as live load for gravity and dead load for seismic load.

Because of the probable relationship between partition loads and occupancy loads, the whole question of whether a load allowance should be made for moveable and future partitions requires further research and detailed study.

\subsection{Earth Pressure}

The requirements covering earth pressures have been rewritten to allow the use of strength design based upon the load factors included in Part 1.

A partial safety factor of 1.5 should be applied to the average measured soil strengths when using strength design.

Design methods for lateral loads on earth retaining structures during earthquakes are given in the paper by seed \& Whitman referred to in Commentary Clause C2.1.3.1. An additional reference is "Retaining Wall Design Notes" prepared in the office of the Chief Designing Engineer, MWD (II).

Clause 1.2.6 Part I now covers stability and the previous working stress requirement that retaining walls should have a factor of safety of 1.5 against overturning or sliding instability has been dropped. Clause $\mathrm{C} 3.7$ of part 3 in dealing with horizontal support for retaining walls comments that "passive pressure of the ground or by friction between foundation and the soil can be adequate"!

The surcharge due to traffic loading on public footpaths has been reduced to the more realistic figure of $5 \mathrm{kPa}$ (previously it was $10 \mathrm{kPa}$ ) while for public roadways the loading remains $10 \mathrm{kPa}$. Note that private roadways and footpaths are treated separately on the basis of anticipated traffic loadings.

An important aspect now required to be considered in the design is the construction method (see also Clause 2.1.5). Consideration must be given to the effects of exceptional loadings and surcharge due to methods of compaction and backfill.

\subsection{Temperature Effects}

Except for the rewording of the first sentence and the inclusion of temperatures in degrees celcius the clause is as the previous code.

\subsection{Loads During Construction}

This is a new clause of a rather general nature which covers loads during construction and requires precautions to be taken to protect the building from damage or distortion during construction. There appears to be no good reason to include this type of load under the general heading of a dead load. 
Basic minimum uniformity distributed live loads are set out in some detail in Table 1. It is believed that by setting out the types of loads to be found under each occupancy heading the choosing of loads is made more easily (and possibly more accurately) than in the previous code.

As discussed earlier the loads in the table are deterministic and the original basis for some is not clear nor completely rational.

It seems extraordinary that so much is known on the ultimate strength of members, on material properties and on the statistical evaluation of these properties and yet so little is known of the loads and variations of load that the same members will be required to safely carry during its life. This is highlighted by the introduction of BSCPIIO (2) which is based upon a limit state design basis but because of a lack of statistical information in loading the potential of the limit state approach cannot be fully utilised.

The levels of loading currently used for various occupancies have been arrived at over the years presumably on the basis of experience and engineering judgement. Apparently the level of loading currently adopted together with present methods of design and construction produce structures which are safe and have sufficient stiffness to meet serviceability requirements.

Very few soundly based floor loading surveys have been carridd out. Notable exceptions are those by Mitchell \& Woodgate and the current surveys at present nearing completion for NBS in U.S.A. As far as is known only one or two loading surveys have been carried out on office buildings in New Zealand and these were carried out by the M.W.D.

The level of live loads has been based upon BSCP 3 Chapter V(12), AS1170.1 - 1971 (10) and the existing Chapter 8: 1965.

An important reduction in live load included in Table 1 is that applying to offices. The loading for floors (apart from ground floors) has been reduced to $2.5 \mathrm{kPa}$. from the previous $3.0 \mathrm{kPa}$. This now brings New Zealand into line with overseas codes such as Britain and U.S.A. Continental countries use even lower values.

An important consideration noted in the commentary Clause C2.2.1.1 is that generally the loads do not allow for possible change of occupancy nor do they allow for high density mobile storage. These are matters which should be given detailed consideration by the designer in consultation with the client at an early stage in the planning of the project.

For the office occupancy ground floor offices and public areas are allocated higher floor loadings than offices on the other floors. Load surveys (13) justify such a differentiation. Whether public areas need to be designed for such levels of loading is questionable. Mitchell \& Woodgate (13) referring to the crowding which could occur during fire practice drill arrive at a loading of $2.4 \mathrm{kPa}$ based upon the packing of people to the point where shuffling ceases and the area occupied per person is $0.26 \mathrm{~m}^{2}$.

\subsection{Ceiling Joists and Supporting Members}

The requirement that ceiling joists and supporting members to ceiling spaces with access for maintenance only be designed for a point load of $I \mathrm{kN}$ is new. This is a logical requirement as it allows for the loading due to a man in any likely position carrying out routine maintenance work. Where appropriate this clause would require the bottom chords of roof trusses to be designed accordingly. The fact that this requirement did not apply in the past without any apparent ill effects should not be used as a criteria for the future when more realistic design methods and new materials may be available.

\subsection{Grandstands}

The present code has no requirement covering the horizontal loads to be applied to the seats of grandstands and similar buildings nor to platforms without seats. These have now been included. It should be noted that these loads are to be treated separately and are not additive to the seismic horizontal loads.

\subsection{Storage Loads}

Clause 8.14.5 in the existing code has been retained apart from minor changes in wording. The clause covers extra heavy loads and goods causing loadings in excess of $10 \mathrm{kPa}$ which are not included in Table 1 .

The heading 'Storage Loads' is somewhat inappropriate:

\subsection{Reduced Live Loads}

This is a new clause and is based upon the reduction of live load procedures of the National Building Code of Canada (1970).

The reason for adopting this approach is that the reductions appear to be more reasonable when compared to load survey results than other current reduction formulae used in oyerseas codes such as AS 1170 Part 1 - 1971 (I0).

The use of $R$ applies to live loads on tributary areas of all types of structural members but the reduction is not intended to apply to snow load or to roof loads applied to roofs without access. (Type 2 loads of Table 2 Clause 2.2.2.1.)

A comparison of the proposed reduction formula with other methods including Clause 8.19. Chapter 8 and the results of load. surveys is given in Fig. 1 .

\subsection{Concentrated Loads}

As well as uniformly distributed loads Table 1 also includes concentrated loads for each occupancy. Such loads appear to be necessary to provide for the greater and more extended use of lightweight floors of various types in the future. Whether such concentrated loads are justified as such is questionable. In the loading surveys carried 
out by Mitchell and Woodgate (13) it was not possible to identify an alternative concentrated load suitable for use in design. Loading concentrations were found to vary in intensity and in area occupied according to the size of bay considered. As a result Mitchell \& Woodgate (I3) advocate the use of Load Concentration Factors which take into account such variations and their effects on moments and shears.

\subsection{Live Loads for Roofs and Verandahs}

The provisions for live loads to roofs and verandahs with and without access are new. For roofs without access the provisions are based upon AS 1170 part 1 - 1971 (10). The loads for verandahs with no access but over public spaces are the same as roofs and verandahs with access. This provision was included as a result of a survey of local bodies who produced evidence and argument that all such verandahs could be loaded with spectators many times during their life.

The point load of $1.0 \mathrm{kN}$ specified in Table 2 should be applied over a square with a 0.1 metre side.

\subsection{Snow Loads}

The section on snow loads is completely new and is based upon work by Pinnell (14) at NZAEI and subsequent information on snow loads supplied by the N.Z. Meteorological Service.

The provisions attempt to provide useable and complete as possible information on snow loads effects while retaining simplicity of application to design. For more important or unusual or large buildings designers are referred to the National Building Code of Canada (1970) for additional data on accumulation of snow.

A distinct departure from overseas practice is the use of the open field snow load' $f$ as the basic design load.

It should be noted that snow load is not defined as a live load in 1.1.3.

\subsection{Ponding}

This is a completely new clause which draws the designers attention to the problem of retention of water due to deflection when inadequate falls or stiffness are built into a roof structure or verandah. There have been a number of failures of structures in the U.S.A. due to this cause which is not restricted to a single material or roofing system. The problem could be of greater significance now that the live load on roofs has been reduced significantly by clause 2.2.2. Methods of dealing with ponding are given in clause 1.13 of the 1969 Specification and Commentary of the A.I.S.C.

\subsection{Live Loads for Balustrades and Parapets}

Clause 8.17 of the existing code has been retained without alteration.

\subsection{Moving Live Loads}

There appeared to be no reason to change clause 8.18 as promulgated in amendment 3 and this has been incorporated in the code. To be consistent, however, 'lateral force' has been altered to 'horizontal force'.

\subsection{Total Reduced Gravity Load}

As in Clause 8.22 of Chapter 8 a reduced live load may be used for calculating the horizontal seismic force. An important change, however, is that this reduced load is not now to be used as the live load acting concurrently with earthquake and dead load in the design of a member. The live load to be used in the appropriate design load equation is the reduced live load $\mathrm{I}_{R}$ determined in clause 2.2 .4 .

As comparison of the effect of this change on moment envelopes for ground floor and second floor beams of a 3 storey and 14 storey $\mathrm{RC}$ building has already been made by Glogau (I6).

To simplify calculations the reduced gravity load wt may be taken as $D$ for live loads up to and including $1.5 \mathrm{kPa}$ for all types of buildings and as 1 . ID for ordinary buildings with normal weight distribution and with normal weight concrete floors for live loads up to and including $5 \mathrm{kPa}$

\subsection{CONCLUSION}

The provisions of the code covering dead, live, snow loads etc. deal with these loads in much more detail than the existing code. It is believed that they will clarify a number of areas which have caused difficulties in the past as well as giving more realistic loadings such as roofs.

Hopefully, this will be the last revision of this part of the code on a purely deterministic basis.

\section{APPENDIX I.}

\section{References}

1. Reid S. G. (1975), "Probability - Based Design and a Probabilistic Code Format" Dept. of Civil Engineering, University of Canterbury.

2. (1972) "The Structural Use of Concrete", CP110: Part I BSI.

3. (1972) "General Principles for the Verification of the Safety of Structures" ISO.

4. (1974) Draft on Serviceability Limit State Deformation. ISO $25 \mathrm{E}$.

5. (1974) "The Principles of Limit Stage Design". DR 74056 SAA.

6. (1971) "Building Code Requirements for Reinforced Concrete" ACI 318-71 ACI.

7. (1963) "Building Code Requirements for Reinforced Concrete". ACI 318-63 ACI.

8. (1970) "Reinforced Concrete Design". NZS $3101 \mathrm{P}$ SANZ.

9. (1964) "Weights of Building Materials". BS 648 .

10. (1971) "SAA Loading Code". AS 1170 Part I SAA.

11. (1973) "Retaining Wall Design Notes". MWD.

12. (1967) Dead and Imposed Loads CP3: Chapter V Loading Part I BSI.

13. Mitchell, G. R. \& Woodgate, R. W. (1971), "Floor Loadings in Office Buildings - 
the Results of a Survey", BRS CP $3 / 71$.

14. Pinnell, G. C. (1974). "Snow Damage to Buildings", NZAEI Internal Report No. 48 (Unpublished).

15. (1969) "Specification of Structural
Steel for Buildings", AISC.

16. Glogau, O. A. (1972), "The Objective of the New Zealand Seismic Design Code" Structural Design for Earthquakes, University of Auckland.

TABLE A

\section{DESIGN LOAD EQUATIONS FOR COMBINATIONS OF LOADING}

From Clauses 1.3 .2 and 1.3 .3 of NZS 4203 Part 1

LOADING COMBINATION
1. Dead \& Iive Loads
2. Dead, Live \& Wind Loads
3. Dead, Live \& Earthquake
Loads
4. Dead, Snow \& Wind Loads
5. Dead, Live \& Lateral Earth
Pressure
6. Dead, Live \& Liquid
Pressure
STRENGTH METHOD (ULTIMATE LIMIT STATE CONDITION)

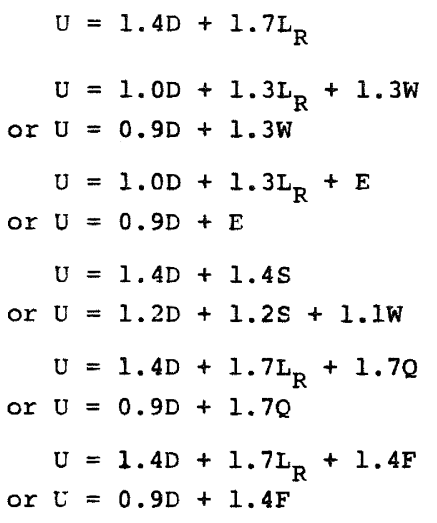

TABLE B

COMPARISON OF DESIGN LOAD EQUATIONS FROM: VARIOUS CODES

$\begin{array}{ccccccc}\text { CODE } & \text { AISC } & \text { NZ3101P } & \text { CEB } & \text { ACI } 318-71 & \text { BSCPI10 } & \text { SEAOC } \\ \text { DATE } & 1969 & 1970 & 1970 & 1971 & 1972 & 1973 \\ \text { MATERIAL } & \text { STEEL } & \text { R.C. } & \text { R.C. } & \text { R.C. } & \text { R.C. } & \text { R.C. }\end{array}$

I. DESIGN METHODS

\begin{tabular}{|c|c|c|c|c|c|c|}
\hline & $\begin{array}{l}\text { Plastic } \\
\text { Design }\end{array}$ & $\begin{array}{l}\text { Strength } \\
\text { Method }\end{array}$ & $\begin{array}{l}\text { Ultimate } \\
\text { Limit State }\end{array}$ & $\begin{array}{l}\text { Strength } \\
\text { Method }\end{array}$ & $\begin{array}{l}\text { Ultimate } \\
\text { Limit State }\end{array}$ & $\begin{array}{l}\text { Strength } \\
\text { Method }\end{array}$ \\
\hline Dead \& Live & $1.7 \mathrm{D}+1.7 \mathrm{~L}$ & $1.5 \mathrm{D}+1.8 \mathrm{~L}$ & $1.4 \mathrm{D}+1.6 \mathrm{~L}$ & $1.4 \mathrm{D}+1.7 \mathrm{~L}$ & $1.4 \mathrm{D}+1.6 \mathrm{I}$ & \\
\hline $\begin{array}{l}\text { Dead, Live \& } \\
\text { Earthquake }\end{array}$ & 1. $3 D+1.3 L+1.3 E$ & $\begin{array}{l}1.25 \mathrm{D}+1.25 \mathrm{Le} \\
+1.25 \mathrm{E}\end{array}$ & $1.25 \mathrm{D}+1.6 \mathrm{E}$ & $\begin{array}{l}1.05 \mathrm{D}+1.27 \mathrm{~L} \\
+1.4 \mathrm{E}\end{array}$ & - & $\begin{array}{l}1.4 \mathrm{D}+1.4 \mathrm{~L}+1.4 \mathrm{E} \text { or } \\
0.9 \mathrm{D}+1.4 \mathrm{E} \\
\text { Shear Diagonal } \\
\text { Tension (Except } \\
\mathrm{K}=0.67 \text { ) } \\
1.4 \mathrm{D}+1.4 \mathrm{~L}+2.8 \mathrm{E} \text { or } \\
0.9 \mathrm{D}+2.8 \mathrm{E}\end{array}$ \\
\hline $\begin{array}{l}\text { Dead, Live \& } \\
\text { Wind }\end{array}$ & $1.3 D+1.3 L+1.3 W$ & $\begin{array}{l}1.25 \mathrm{D}+1.25 \mathrm{~L} \\
+1.25 \mathrm{~W} \text { or } \\
0.9 \mathrm{D}+1.25 \mathrm{~W}\end{array}$ & $\begin{array}{l}1.25 \mathrm{D}+1.25 \mathrm{~L} \\
+1.25 \mathrm{~W} \text { or } \\
1.0 \mathrm{D}+1.6 \mathrm{~W}\end{array}$ & $\begin{array}{c}1.05 D+1.27 \mathrm{I} \\
+1.27 \mathrm{~W} \text { or } \\
0.9 \mathrm{D}+1.3 \mathrm{~W}\end{array}$ & $\begin{array}{l}1.2 \mathrm{D}+1.2 \mathrm{~L}+1.2 \mathrm{~W} \\
\text { or } 0.9 \mathrm{D}+1.4 \mathrm{~W}\end{array}$ & ACI \\
\hline
\end{tabular}

II. SERVICEABILITY REQUIREMENTS OR LIMIT STATES DEFLECTION, CRACKING, VIBRATION

Dead \& Live

Dead \& wind

Dead, Live \&

Wind

\author{
$1.0 D+1.0 L$ \\ Service loads \\ $1.0 D+1.0 \mathrm{~L}$ \\ 1. $O D+0.8 I+0.8 W$ \\ (Clause 9.5.1) \\ $1.0 D+1.0 W$ \\ or $I$ or \\ sustained load \\ $1.0 \mathrm{D}+0.8 \mathrm{~L}+0.8 \mathrm{~W}$ \\ Clause 9.5.2.4.
}


FIGURE 1 : COMPARISON OF VARIOUS LIVE LOAD REDUCTION FORMULA - OFFICE FLOOR LOADS

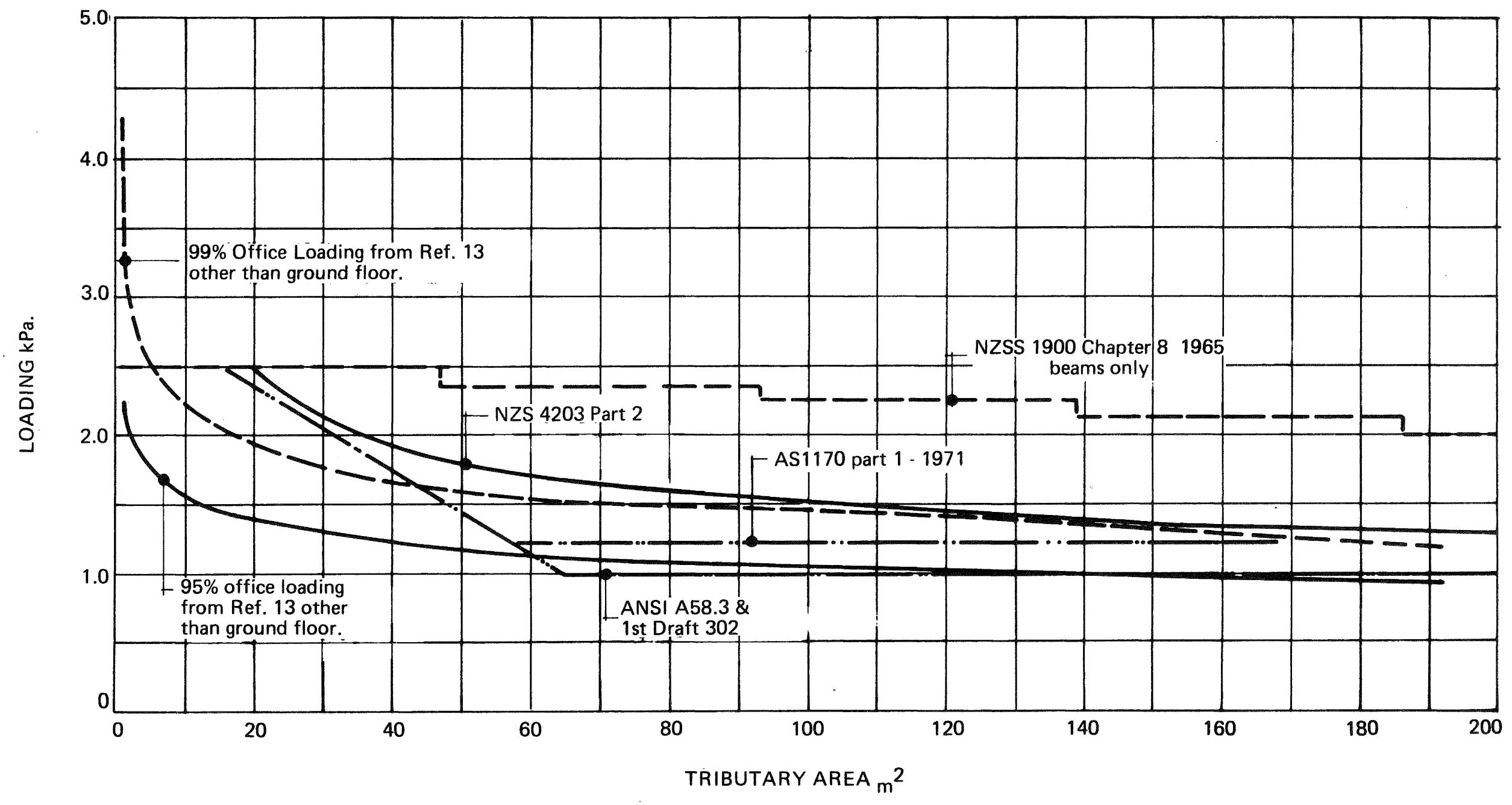

